\title{
Detection of Small Neutral Carbohydrates Using Various Supporting Materials in Laser Desorption/Ionization Mass Spectrometry
}

\author{
Hyo-Jik Yang, Aera Lee, Myung-Ki Lee, ${ }^{\dagger}$ Woong Kim, ${ }^{\dagger}$ and Jeongkwon Kim* \\ Department of Chemistry, Chungnam National University, Daejeon 305-764, Korea. *E-mail: jkkim48105@cnu.ac.kr \\ ${ }^{\dagger}$ Department of Materials Science and Engineering, Korea University, Seoul 136-701, Korea \\ Received October 6, 2009, Accepted December 8, 2009
}

\begin{abstract}
A comprehensive comparative investigation of small carbohydrates in laser desorption ionization was performed on supporting materials composed of sodiated 2,5-dihydroxybenzoic acid (DHB), carbon nanotubes, an ionic liquid matrix of DHB-pyridine, a binary matrix of DHB-aminopyrazine, zinc oxide nanoparticles, and gold nanoparticles. The abundance of $[\mathrm{M}+\mathrm{Na}]^{+}$ions, where $\mathrm{M}$ is glucose or sucrose, was compared for each supporting material. The highest sensitivity for both glucose and sucrose, with a detection limit of 3 pmol, was observed with carbon nanotubes. Both carbon nanotubes and the ionic liquid matrix exhibited the highest reproducibility.
\end{abstract}

Key Words: Carbohydrate, Laser desorption ionization, Ionic liquid matrix, MALDI, Binary matrix

\section{Introduction}

Carbohydrates are one of the major classes of biomolecules. Glucose $\left(\mathrm{C}_{6} \mathrm{H}_{12} \mathrm{O}_{6}\right)$ is an important monosaccharide in biology and is used by living cells as a source of energy and as a metabolic intermediate in most organisms. Sucrose $\left(\mathrm{C}_{12} \mathrm{H}_{22} \mathrm{O}_{11}\right)$ is a disaccharide composed of glucose and fructose. These small, neutral carbohydrates are detected as $[\mathrm{M}+\mathrm{Na}]^{+}$and $[\mathrm{M}+\mathrm{K}]^{+}$in positive ion mode matrix-assisted laser desorption/ionizationmass spectrometry (MALDI-MS) due to the deficiency of basic functional groups in the carbohydrates to which a proton can attach and the presence of $\mathrm{Na}^{+}$and $\mathrm{K}^{+}$in distilled water. ${ }^{1}$ To improve the signal of carbohydrates in MALDI-MS analyses, sodium ions are often intentionally added to sample solutions. ${ }^{2}$

MALDI-MS typically suffers from high background interference in the low $\mathrm{m} / \mathrm{z}$ region in common organic matrices such as $\alpha$-cyano-4-hydroxycinnamic acid (CHCA) and 2,5-dihydroxybenzoic acid (DHB). ${ }^{3}$ Many alternative matrices such as metal, ${ }^{4-6}$ metal oxide, ${ }^{7}$ and porous silicon ${ }^{8}$ have been evaluated to eliminate this background. Since these investigations did not use conventional organic matrices, the technique is often referred to as laser desorption ionization (LDI)-MS instead of the more conventional MALDI-MS. Recently, carbon nanotubes were used to detect low-molecular-weight analytes such as amino acids, ${ }^{2,9}$ peptides, organic compounds, and small neutral carbohydrates. ${ }^{2,3,10,11}$ Another alternative method employed a combination of ionic liquids and organic MALDI matrices ${ }^{12-15}$ or a binary matrix. ${ }^{16,17}$ Surface-assisted laser desorption/ionization (SALDI) has recently been introduced using supporting materials such as gold $(\mathrm{Au})$ nanoparticles, ${ }^{4,5}$ silver nanoparticles, ${ }^{6}$ or zinc oxide $(\mathrm{ZnO})$ nanoparticles. ${ }^{7}$ Material-enhanced laser desorption/ionization, which is based on the surface modification of a silica gel with energy-absorbing substances, has been introduced for the analysis of carbohydrates ${ }^{18}$ and amino acids. $^{19}$

In the current study, glucose and sucrose were analyzed by positive ion LDI using a sodiated DHB matrix, carbon nanotubes, an ionic liquid matrix of DHB-pyridine, a binary matrix of DHB-aminopyrazine, and SALDI materials such as $\mathrm{ZnO}$ nanoparticles and Au nanoparticles. This comprehensive investigation provides valuable information regarding the analysis of small carbohydrates using LDI.

\section{Experimental Section}

Materials. Glucose, sucrose, pyridine, acetonitrile ( $\mathrm{ACN})$, trifluoroacetic acid (TFA), $\mathrm{Zn}\left(\mathrm{CH}_{3} \mathrm{COO}\right)_{2}, \mathrm{H}_{2} \mathrm{C}_{2} \mathrm{O}_{4} \cdot 2 \mathrm{H}_{2} \mathrm{O}$, DHB, $\mathrm{HAuCl}_{4} \cdot 3 \mathrm{H}_{2} \mathrm{O}\left(99.9 \%\right.$ ), trisodium citrate, $\mathrm{NaBH}_{4}$, and trifluoroacetic acid sodium salt (Na-TFA) were purchased from SigmaAldrich (St. Louis, MO, USA). Multi-walled carbon nanotubes (MWCNTs) were obtained from LG Chemical (Daejeon, Korea) and MALDI plates ( $\mu$ Focus) were acquired from Hudson Surface Technology, Inc. (Newark, NJ, USA).

Preparation of supporting materials. The DHB and sodiated DHB matrices were prepared by the addition of $10 \mu \mathrm{L}$ of pure TFA or $2.85 \mathrm{M}$ aqueous $\mathrm{Na} \cdot \mathrm{TFA}$ to $1 \mathrm{~mL}$ of $20 \mathrm{mg}$ DHB in $50 \%$ $\mathrm{ACN} /$ water (v/v), respectively. Carbon nanotube solutions were prepared by mixing multi-walled carbon nanotubes ${ }^{20}$ in dimethylfuran $(0.00066 \% \mathrm{w} / \mathrm{v})$ with an equal volume of $\mathrm{CH}_{3} \mathrm{OH}$ to accelerate solvent evaporation after sample deposition onto the MALDI plate. Ionic liquid matrices of DHB-pyridine were prepared by adding $10 \mu \mathrm{L}$ of $2.85 \mathrm{M}$ aqueous $\mathrm{Na} \cdot \mathrm{TFA}$ and $4 \mu \mathrm{L}$ pyridine to $1 \mathrm{~mL}$ of $50 \% \mathrm{ACN} /$ water $(\mathrm{v} / \mathrm{v})$ solution with $77 \mathrm{mg}$ DHB, which yielded a $1: 10$ molar ratio of pyridine : DHB. A binary matrix was prepared by adding $10 \mu \mathrm{L}$ of $2.85 \mathrm{M}$ aqueous $\mathrm{Na} \cdot \mathrm{TFA}$ and $10 \mathrm{mg}$ aminopyrazine to $1 \mathrm{~mL}$ of $50 \% \mathrm{ACN} /$ water (v/v) solution with $30 \mathrm{mg}$ DHB, which yielded a $3: 1$ weight ratio of DHB : aminopyrazine. ${ }^{17}$

$\mathrm{ZnO}$ nanoparticles were synthesized by a solution-free mechanochemical reaction. ${ }^{21}$ Briefly, $0.1 \mathrm{~mol}$ of $\mathrm{Zn}\left(\mathrm{CH}_{3} \mathrm{COO}\right)_{2}$ and 0.12 mol of $\mathrm{H}_{2} \mathrm{C}_{2} \mathrm{O}_{4} \cdot 2 \mathrm{H}_{2} \mathrm{O}$ were mixed by grinding in an agate mortar for $30 \mathrm{~min}$ at room temperature, forming $\mathrm{ZnC}_{2} \mathrm{O}_{4}$. $2 \mathrm{H}_{2} \mathrm{O}$ nanoparticles. $\mathrm{ZnO}$ nanoparticles $(\sim 30 \mathrm{~nm}$ diameter) were then prepared by thermal decomposition of the $\mathrm{ZnC}_{2} \mathrm{O}_{4} \cdot 2 \mathrm{H}_{2} \mathrm{O}$ nanoparticles at $450{ }^{\circ} \mathrm{C}$ for $30 \mathrm{~min}$. The $\mathrm{ZnO}$ nanoparticles $(10$ $\mathrm{mg}$ ) were suspended in $1 \mathrm{~mL}$ of $50 \% \mathrm{ACN} /$ water (v/v) solution 
and ultrasonically agitated for $2 \mathrm{~h}$. Aqueous Na.TFA $(10 \mu \mathrm{L}$, $10 \mathrm{mM}$ ) was added as a cationizing agent. Water-dispersed $\mathrm{Au}$ nanoparticles $(7 \mathrm{mg} / \mathrm{mL})$ were synthesized as follows. First, 20 $\mathrm{mL}$ of aqueous solution containing $0.25 \mathrm{mM} \mathrm{HAuCl}_{4} \cdot 3 \mathrm{H}_{2} \mathrm{O}$ and $0.25 \mathrm{mM}$ trisodium citrate was prepared in a flask. Then, $0.6 \mathrm{~mL}$ of a cold, freshly prepared $0.1 \mathrm{M} \mathrm{NaBH}_{4}$ solution was added while stirring. The development of a pink solution indicated the formation of Au nanoparticles ( $\sim 7 \mathrm{~nm}$ diameter). In a final step, the Au nanoparticle solution $(990 \mu \mathrm{L})$ was mixed with 10 $\mu \mathrm{L}$ of $10 \mathrm{mM}$ aqueous $\mathrm{Na} \cdot \mathrm{TFA}$.

Preparation of sample solutions. Glucose and sucrose solutions were prepared in distilled water at a concentration of $1 \mathrm{M}$. All samples were diluted in series from $0.5 \mathrm{M}$ to $0.5 \mu \mathrm{M}$, or from $0.3 \mathrm{M}$ to $0.3 \mu \mathrm{M}$. A modified dried-droplet sample deposition method ${ }^{22}$ was employed for MALDI-TOF analyses, whereby $1 \mu \mathrm{L}$ of the supporting material was deposited onto the MALDI plate, followed by $1 \mu \mathrm{L}$ of the sample solution.

Mass spectrometry. All mass spectra were obtained using a Kratos Axima CFR (Shimadzu, Kyoto, Japan) time-of-flight mass spectrometer equipped with a 337-nm nitrogen laser. In total, 200 shots were accumulated in linear positive ion mode MS. Signals were obtained between $\mathrm{m} / \mathrm{z} 50$ and 1000 .

\section{Results and Discussion}

Sodiated glucose and sucrose in a DHB matrix. MALDIMS analyses of small, neutral carbohydrates such as glucose or sucrose is difficult in positive ion mode because small carbohydrates contain only alcohol groups, which are not protonated under typical MALDI conditions. To improve ionization efficiency, the addition of a metal ion, usually $\mathrm{Na}^{+}$, is often employed. ${ }^{2}$ In the positive ion MALDI-MS analysis of oligosaccharides, DHB provided better performance than $\mathrm{CHCA}$ and sinapinic acid in terms of reproducibility, $\mathrm{S} / \mathrm{N}$ ratio, and matrix suppression effects. ${ }^{1}$ Figure 1 shows the mass spectra of $3.3 \mathrm{nmol}$ each of glucose and sucrose with (a) the DHB matrix and (b) the sodiated DHB matrix. The DHB matrix alone did not produce any protonated or sodiated peaks of glucose or sucrose, while sodiated DHB confidently generated peaks of both species at $\mathrm{m} / \mathrm{z} 203.1$ and 365.1, respectively. No protonated peaks of glu- cose or sucrose were observed. The mass spectra were calibrated by using the DHB matrix peaks at $m / z$ 137.0 $\left[\mathrm{DHB}-\mathrm{H}_{2} \mathrm{O}+\mathrm{H}\right]^{+}$,

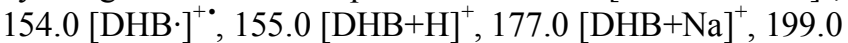
$[\mathrm{DHB}-\mathrm{H}+2 \mathrm{Na}]^{+}$, and $273.1\left[2 \mathrm{DHB}-\mathrm{H}_{2} \mathrm{O}-\mathrm{OH}\right]^{+} .1,9,12$ The peaks at $\mathrm{m} / \mathrm{z} 332.4$ and $\mathrm{m} / \mathrm{z} 360.4$ originated from the stainless steel MALDI plate. All mass spectra represent the summation of 200 laser shots. Broadening of matrix peaks, with a consequent decrease in resolution, was observed in mass spectra created with more than 200 shots. Due to the interference from DHB matrix peaks, glucose and sucrose were only detected down to 333 pmol.

Carbon nanotubes as a matrix material. Carbon nanotubes have been successfully used as an alternative to conventional organic matrices for low molecular mass $(\mathrm{m} / \mathrm{z}<1000)$ analytes, ${ }^{3,9-11}$ including amino acids, peptides, and small carbohydrates. The carbon nanotubes function as both energy receptacles for laser radiation and as energy transporters for desorption/ ionization of analyte ions ${ }^{3}$ due to a combination of their large surface area and strong UV absorption. ${ }^{9}$ Ren et al. used immobilized carbon nanotubes as a MALDI matrix and observed abundant signals with $1 \mathrm{nmol}$ glucose or $1 \mathrm{nmol}$ sucrose. ${ }^{3}$

The mass spectra of carbon nanotubes and a mixture of glucose and sucrose (3.3 nmol each) with carbon nanotubes as a supporting material are shown in Figures 2(a) and 2(b), respectively. No Na·TFA was added to the carbon nanotube solutions unlike the other supporting materials since generally no sodium ion was added in the LDI experiments using carbon nanotubes. ${ }^{3,10,11}$ Sodiated and potassiated peaks of glucose or sucrose in Figure 2(b) are believed to be due to the existence of the alkali metal ions which are intercalated into the carbon nanotubes during the preparation of the carbon nanotubes. Intercalation of alkali metals into carbon nanotubes has already been reported. ${ }^{23,24}$ The disappearance of characteristic nanotube peaks at $\mathrm{m} / \mathrm{z} 120.0$ and $\mathrm{m} / \mathrm{z} 240.0$ with the addition of the carbohydrate sample in Figure 2(a) provides strong evidence for the transfer of absorbed energy from the carbon nanotube matrix to the sample. The lowest detectable level of glucose and sucrose was 3 pmol. Wang et al. used oxidized carbon nanotubes in the analysis of glucose and sucrose with MALDI-Fourier transform mass spectrometry (FTMS) and obtained the detection limit (a)

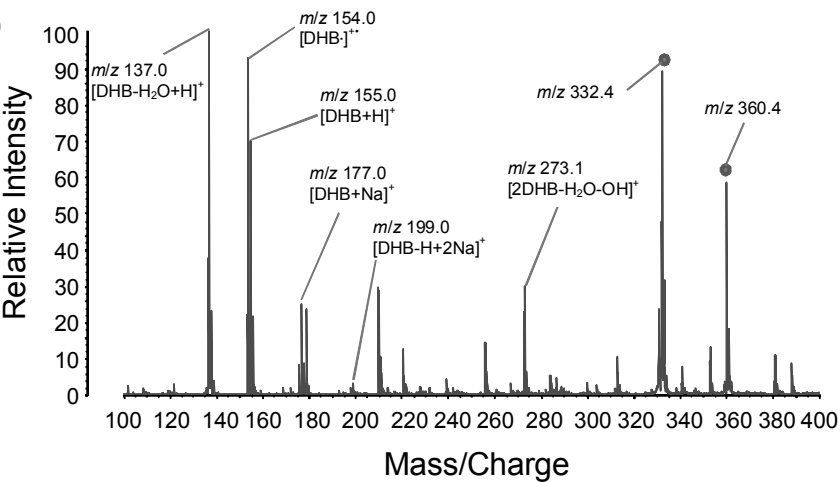

(b)

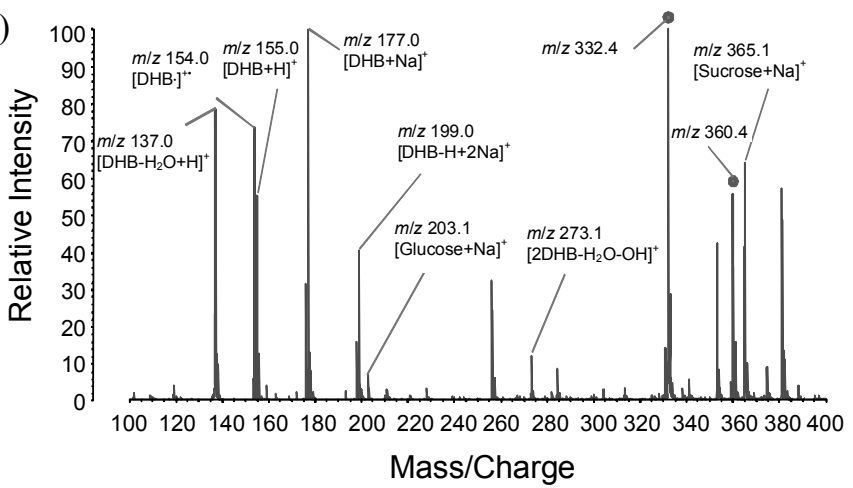

Figure 1. MALDI mass spectra of $3.3 \mathrm{nmol}$ each of glucose and sucrose with (a) the DHB matrix in $50 \%$ ACN/water with $0.1 \%$ TFA and (b) DHB matrix in $50 \% \mathrm{ACN} /$ water with Na.TFA. Glucose and sucrose were detected only in (b) as $\mathrm{Na}^{+}$adducts. DHB derivative peaks appeared at $m / z 137.0\left[\mathrm{DHB}-\mathrm{H}_{2} \mathrm{O}+\mathrm{H}\right]^{+}, 154.0[\mathrm{DHB} \cdot]^{+*}, 155.0[\mathrm{DHB}+\mathrm{H}]^{+}, 177.0[\mathrm{DHB}+\mathrm{Na}]^{+}, 199.0[\mathrm{DHB}-\mathrm{H}+2 \mathrm{Na}]^{+}$, and $273.1\left[2 \mathrm{DHB}-\mathrm{H}_{2} \mathrm{O}-\mathrm{OH}\right]^{+}$. The peaks at $\mathrm{m} / \mathrm{z} 332.4$ and $\mathrm{m} / \mathrm{z} 360.4$ originated from the stainless steel MALDI plate. 
(a)

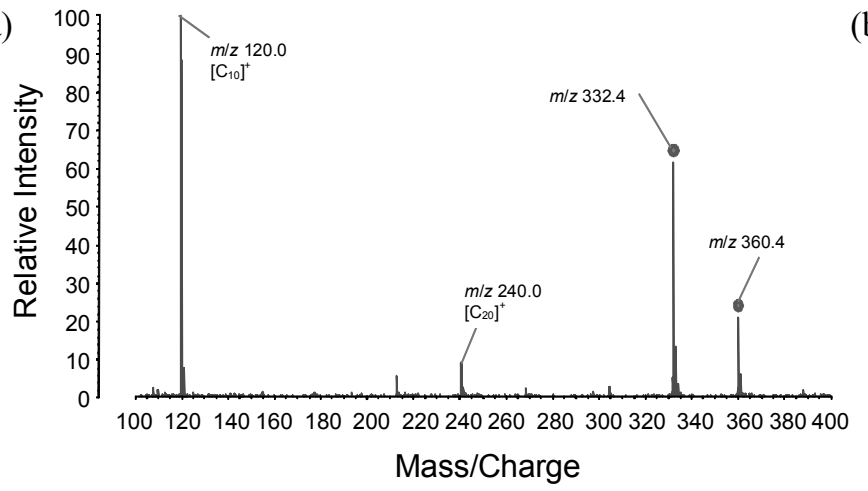

(b)

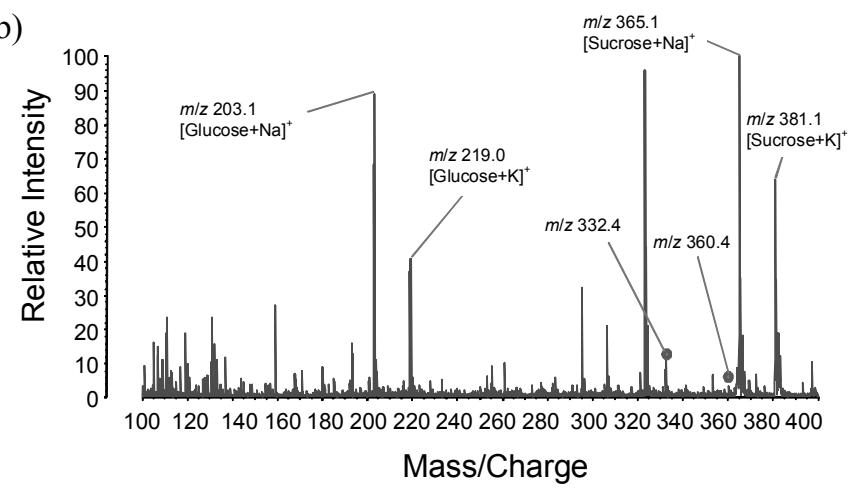

Figure 2. LDI mass spectra of (a) carbon nanotubes and (b) $3.3 \mathrm{nmol}$ each of glucose and sucrose with carbon nanotubes. No cationizing agent was added. The peaks at $\mathrm{m} / \mathrm{z} 332.4$ and $\mathrm{m} / \mathrm{z} 360.4$ originated from the stainless steel MALDI plate.

(a)

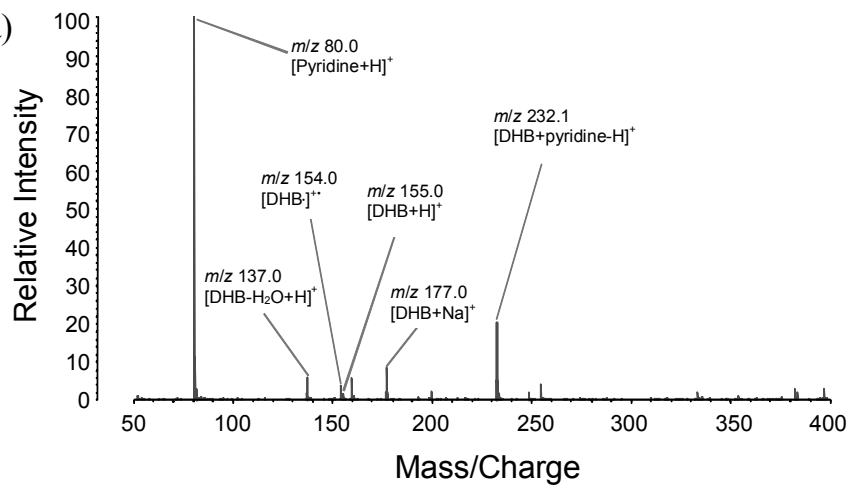

(b)

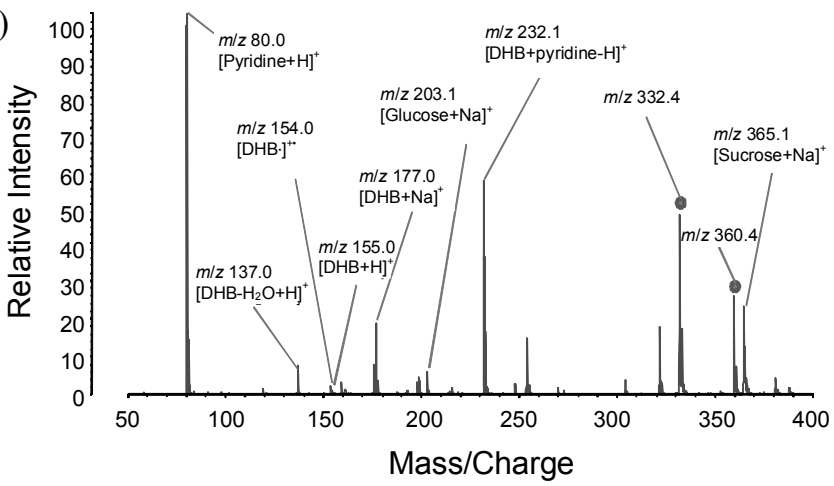

Figure 3. MALDI mass spectra of (a) the DHB-pyridine ionic liquid matrix with Na.TFA and (b) $3.3 \mathrm{nmol}$ each of glucose and sucrose in the same matrix. Peaks indicated with circles are from the DHB matrix. The peaks at $\mathrm{m} / \mathrm{z} 332.4$ and $\mathrm{m} / \mathrm{z} 360.4$ originated from the stainless steel MALDI plate.

of $10 \mathrm{fmol}$, where the superior detection limit is believed to be due to both using oxidized carbon nanotubes and FTMS. ${ }^{11}$

Ionic liquid matrices. Ionic liquid matrices, formed by combining conventional acidic MALDI matrices with organic bases, were introduced to facilitate the mixing of analyte and matrix by inducing a homogeneous distribution of the analyte in sample solutions. ${ }^{12}$ In many cases, the mass spectra of these ionic liquid matrices differed significantly from those of corresponding solid matrices. Ions originating from solid matrices are generally suppressed. ${ }^{13}$ Figure 3 shows mass spectra obtained with an ionic liquid matrix composed of a $1: 10$ molar ratio of DHB : pyridine. An equimolar mixture of DHB and pyridine was also evaluated but exhibited far inferior performance relative to the $1: 10$ mixture. Figure 3(a) shows the mass spectrum of the ionic liquid matrix with two dominant peaks at $\mathrm{m} / \mathrm{z} 80.0$ and 232.1. The peak at $m / z 80.0$ is from a protonated pyridine. The peak at $m / z 232.1$ is believed to originate from the hydride abstraction of an adduct between pyridine and DHB to form $[\mathrm{DHB}+\text { pyridine- } \mathrm{H}]^{+}$. Hydride abstraction and the formation of $[\mathrm{M}-\mathrm{H}]^{+}$ions has been observed in MALDI analyses of piperazine-containing molecules with several common matrices, including DHB, 9-nitroanthracene, 3,4,5-tribydroxybezoic acid, and 2-(4-hydroxyphenylazo)benzoic acid. ${ }^{25}$ In the current study, however, a peak corresponding to the hydride-abstracted pyridine, [pyridine- $\mathrm{H}]^{+}$, was not observed. A reaction involving both DHB and pyridine may have contributed to this hydride abstraction. Further study is needed to clarify the mechanism of this reaction.

Figure 3(b) shows mass spectra of $3.3 \mathrm{nmol}$ each of glucose and sucrose with the DHB-pyridine ionic liquid matrix containing obvious peaks originating from sodiated glucose and sodiated sucrose. The lowest detectable amount of glucose and sucrose was 3 pmol.

Binary matrices. To suppress the background in MALDI-MS analyses of small molecules, binary matrices composed of two different matrix materials have been applied as an alternative matrix. ${ }^{16}$ For oligosaccharides, a $3: 1$ weight ratio of $\mathrm{DHB}$ and 1-hydroxyisoquinoline was most successful. ${ }^{26}$ However, detection below $\mathrm{m} / \mathrm{z} 500$ was still problematic with strong background signals up to $m / z 350 .^{26}$ Recently, a $3: 1$ weight ratio of DHB and aminopyrazine was shown to be very effective in removing the strong background noise from DHB and in improving the sensitivity to carbohydrates. ${ }^{17}$ In the current experiment, a binary matrix consisting of a $3: 1$ weight ratio of DHB and aminopyrazine was evaluated. This mixture results in a dominant peak corresponding to aminopyrazine as shown in Figure 4(a). Figure 4(b) presents the MALDI-MS spectrum of $5.0 \mathrm{nmol}$ each of glucose and sucrose using this binary matrix. The sensitivity was unsatisfactory, with detection limits as high as 500 pmol.

SALDI with ZnO nanoparticles. In 1988, Tanaka et al. used 30-nm inorganic cobalt powders mixed with a liquid matrix of 
(a)

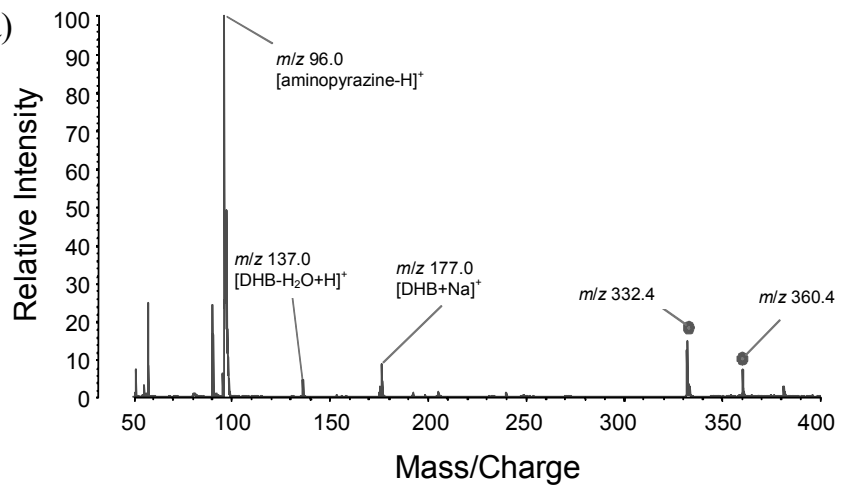

(b)

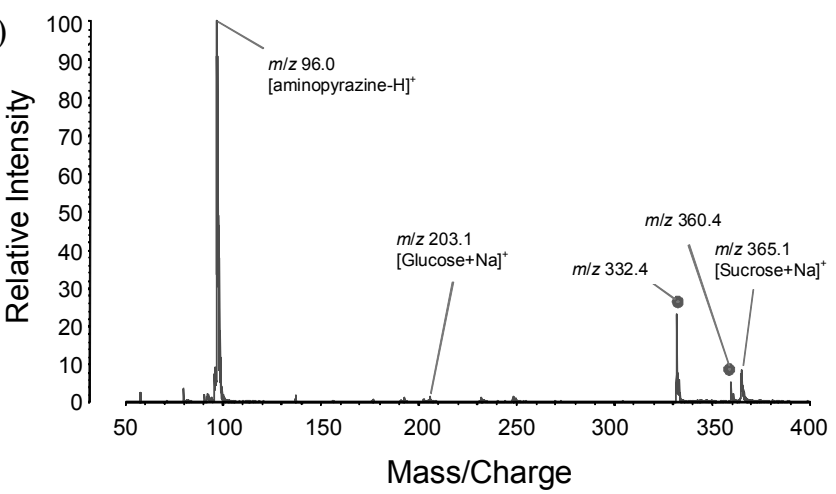

Figure 4. MALDI mass spectra of (a) a binary matrix of DHB-aminopyrazine with Na·TFA and (b) $50.0 \mathrm{nmol}$ each of glucose and sucrose in the same matrix. Peaks indicated with circles are from the DHB matrix. The peaks at $\mathrm{m} / \mathrm{z} 332.4$ and $\mathrm{m} / \mathrm{z} 360.4$ originated from the stainless steel MALDI plate.

(a)

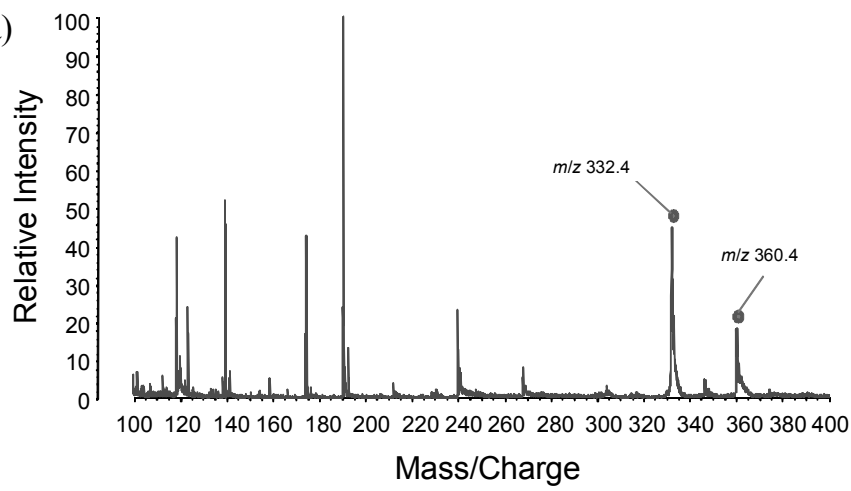

(b)

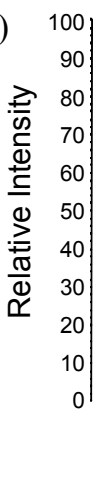

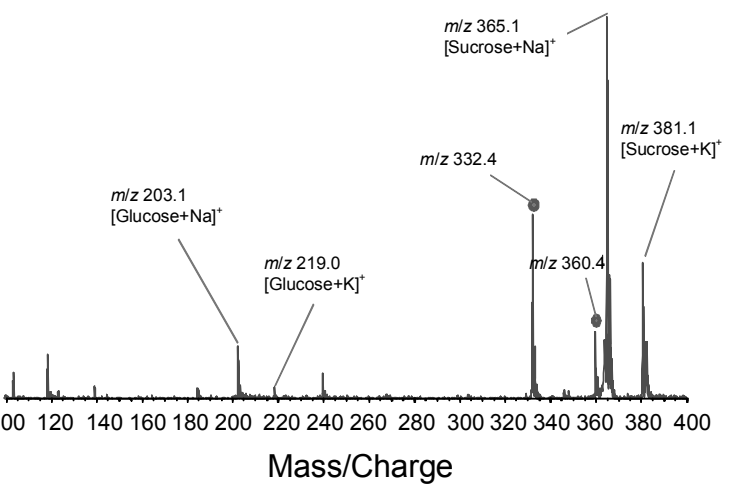

Figure 5. SALDI mass spectra of (a) ZnO nanoparticle supporting materials with Na·TFA and (b) $5 \mathrm{nmol}$ each of glucose and sucrose with the $\mathrm{ZnO}$ nanoparticles. The peaks at $\mathrm{m} / \mathrm{z} 332.4$ and $\mathrm{m} / \mathrm{z} 360.4$ originated from the stainless steel MALDI plate.

glycerol to obtain MALDI-MS spectra of lysozyme. ${ }^{27}$ The cobalt nanoparticles exhibited several properties conducive to desorption/ionization of analyte proteins, including a high surface area, large extinction coefficient at the nitrogen laser band of $337 \mathrm{~nm}$, and a low heat capacity. Sunner et al. developed a SALDI process using $2 \sim 150 \mathrm{~nm}$ graphite particles mixed with glycerol. ${ }^{7}$ Nanoparticles are typically used in SALDI, as opposed to the more conventional organic matrices, to desorb and ionize samples with small molecular mass. ${ }^{4,7}$ In the current work, $\mathrm{ZnO}$ nanoparticles ( $\sim 30 \mathrm{~nm}$ in diameter) were synthesized and used as an alternative SALDI matrix. Several unidentified peaks were observed in the MALDI-MS spectrum of the $\mathrm{ZnO}$ nanoparticles (Figure 5(a)). Figure 5(b) presents the MALDIMS spectrum of $5.0 \mathrm{nmol}$ each of glucose and sucrose with the $\mathrm{ZnO}$ nanoparticles, showing dominant peaks derived from glucose and sucrose. Most of the unidentified ZnO-related peaks disappeared. Detection of glucose and sucrose was successfully performed down to 500 pmol.

SALDI with Au nanoparticles. Au nanoparticles are used widely in chemical biology and in emerging biochemical applications, as well as a supporting material in SALDI-MS. ${ }^{4,5}$ In the current experiment, Au nanoparticles ( $\sim \mathrm{nm}$ in diameter) were synthesized and used in SALDI-MS analyses of glucose and sucrose. The mass spectrum of the Au nanoparticles alone is shown in Figure 5(a). Several distinctive and characteristic peaks were observed at $m / z$ 197.0 $[\mathrm{Au}]^{+}, 220.0[\mathrm{Au}+\mathrm{Na}]^{+}$,
$242.9[\mathrm{Au}+2 \mathrm{Na}]^{+}, 394.0[2 \mathrm{Au}]^{+}$, and $591.0[3 \mathrm{Au}]^{+}$. Figure 6(b) shows the mass spectrum of $5 \mathrm{nmol}$ each of glucose and sucrose deposited on the Au nanoparticle matrix. The distinctive peaks originating from the Au matrix are still visible. The sensitivity was similar to that observed in $\mathrm{ZnO}$ nanoparticles, with reliable detection down to 500 pmol each of glucose and sucrose.

A comparison of each supporting material. Table 1 shows a comparison of peak intensities from glucose and sucrose obtained on each supporting material. All of the supporting materials except sodiated DHB exhibited decreased peak intensities of both glucose and sucrose with high analyte loading (33 nmol or $50 \mathrm{nmol}$ ). This suggests that the amount of supporting material was not adequate to ionize these large amounts of analyte. For the ionic liquid matrix of DHB-pyridine, the linear range of detection extended only from 33 to 333 pmol. With the exception of the high loading point, peak intensities decreased with decreasing amounts of analyte. However, the high relative standard deviations indicate that absolute quantitation is not feasible for MALDI analyses of carbohydrates. Among all of the MALDI matrices evaluated herein, carbon nanotubes and the ionic liquid matrix of DHB-pyridine, with analyte loading between 33 and 333 pmol, provided relatively reproducible results with less than $40 \%$ relative standard deviation.

In most cases, the peak intensities of sucrose were higher than those of glucose. This effect is believed to be due to the higher number of oxygen atoms in sucrose with which sodium 
(a)

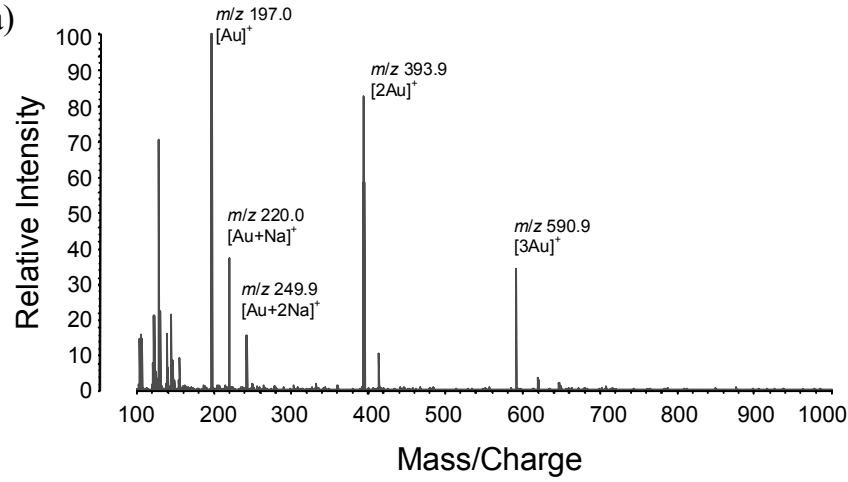

(b)

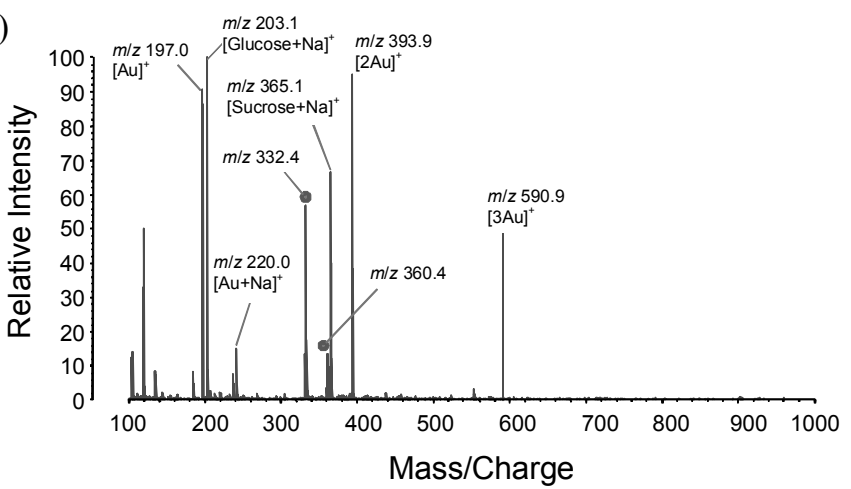

Figure 6. SALDI mass spectra of (a) Au nanoparticle supporting materials with Na-TFA and (b) 5 nmol each of glucose and sucrose with the Au nanoparticles. The peaks at $\mathrm{m} / \mathrm{z} 332.4$ and $\mathrm{m} / \mathrm{z} 360.4$ originated from the stainless steel MALDI plate.

Table 1. The intensity comparison of different supporting materials in MALDI-MS analysis of glucose and sucrose. Four different measurements were performed

\begin{tabular}{|c|c|c|c|c|c|c|c|}
\hline \multirow[b]{2}{*}{$\begin{array}{l}\text { Supporting } \\
\text { materials }\end{array}$} & \multirow[b]{2}{*}{$\begin{array}{l}\text { Loaded amount } \\
\qquad(\mathrm{pmol})\end{array}$} & \multicolumn{3}{|c|}{ Peak intensities of glucose } & \multicolumn{3}{|c|}{ Peak intensities of sucrose } \\
\hline & & Average & $\begin{array}{l}\text { Standard } \\
\text { deviation }\end{array}$ & $\begin{array}{l}\text { \%Relative } \\
\text { standard } \\
\text { deviation }\end{array}$ & Average & $\begin{array}{l}\text { Standard } \\
\text { deviation }\end{array}$ & $\begin{array}{c}\text { \% Relative } \\
\text { standard } \\
\text { deviation }\end{array}$ \\
\hline \multirow{4}{*}{ Sodiated DHB } & 33,333 & 757.9 & 480.8 & 63.4 & $2,422.1$ & $1,327.6$ & 54.8 \\
\hline & 3,333 & 142.4 & 177.6 & 124.7 & 526.5 & 581.8 & 110.5 \\
\hline & 333 & 10.4 & 12.3 & 118.3 & 106.5 & 15.6 & 14.6 \\
\hline & 33 & $\stackrel{a}{a}^{-1}$ & $\stackrel{a}{a}^{-1}$ & $-^{a}$ & 13.3 & 11.1 & 83.5 \\
\hline \multirow{5}{*}{ Carbon Nanotubes } & 33,333 & 136.1 & 112.3 & 82.5 & $-{ }^{a}$ & $-{ }^{a}$ & $-a^{a}$ \\
\hline & 3,333 & $6,003.8$ & $4,757.1$ & 79.2 & $7,470.9$ & $5,859.3$ & 78.4 \\
\hline & 333 & $9,356.3$ & $1,965.2$ & 21.0 & $7,698.3$ & $1,286.2$ & 16.7 \\
\hline & 33 & $2,971.5$ & 737.3 & 24.8 & $4,205.0$ & $1,483.7$ & 35.3 \\
\hline & 3 & $1,246.0$ & 633.5 & 50.8 & $2,881.5$ & $1,469.7$ & 51.0 \\
\hline \multirow{4}{*}{$\begin{array}{l}\text { Ionic liquid matrix } \\
\text { (DHB-pyridine) }\end{array}$} & 3,333 & 148.8 & 264.2 & 177.6 & 933.7 & 949.6 & 101.7 \\
\hline & 333 & $2,083.9$ & 544.5 & 26.1 & $11,940.5$ & 3101.8 & 26.0 \\
\hline & 33 & 532.7 & 202.9 & 38.1 & $3,946.9$ & 1212.7 & 30.7 \\
\hline & 3 & $-{ }^{a}$ & $-a$ & $a^{a}$ & $-a$ & $-a$ & $-a$ \\
\hline \multirow{3}{*}{$\begin{array}{l}\text { Binary matrix } \\
\text { (DHB-aminopyrazine) }\end{array}$} & 50,000 & 413.5 & 776.5 & 187.8 & $2,693.7$ & $3,456.0$ & 128.3 \\
\hline & 5,000 & 670.6 & 283.4 & 42.3 & $4,992.7$ & $2,225.3$ & 44.6 \\
\hline & 500 & $-{ }^{a}$ & $-a$ & $a^{a}$ & $2,570.7$ & $1,201.1$ & 46.7 \\
\hline \multirow{4}{*}{$\mathrm{ZnO}$} & 50,000 & 1.7 & 3.4 & 200.0 & 69.8 & 52.7 & 75.5 \\
\hline & 5,000 & 424.1 & 184.7 & 43.6 & $3,590.8$ & $1,682.1$ & 46.8 \\
\hline & 500 & 105.0 & 76.4 & 72.8 & 327.1 & 654.3 & 200.0 \\
\hline & 50 & 13.0 & 11.0 & 84.6 & $-^{a}$ & $-^{a}$ & $-^{a}$ \\
\hline \multirow{4}{*}{ Gold Nanoparticles } & 50,000 & 176.9 & 156.1 & 88.2 & 97.6 & 119.1 & 122.0 \\
\hline & 5,000 & 871.7 & 760.5 & 87.2 & 756.4 & $1,030.5$ & 136.2 \\
\hline & 500 & 316.0 & 404.2 & 127.9 & 63.9 & 127.9 & 200.2 \\
\hline & 50 & 1.3 & 2.6 & 200.0 & $-{ }^{a}$ & $-{ }^{a}$ & $-{ }^{a}$ \\
\hline
\end{tabular}

${ }^{a}$ Not Detected.

ions can coordinate. ${ }^{1}$ However, with matrices composed of carbon nanotubes and Au nanoparticles, similar peak intensities were observed for both analytes. This implies that these two matrices have different ionization mechanisms than the other supporting materials.

Of all the materials tested, carbon nanotubes exhibited the lowest detection limit for both glucose and sucrose ( 3 pmol), while the highest detection limits were observed with the binary matrix composed of DHB-aminopyrazine ( $5 \mathrm{nmol}$ for glucose and $0.5 \mathrm{nmol}$ for sucrose).

\section{Conclusions}

Sodiated DHB, carbon nanotubes, an ionic liquid matrix of DHB-pyridine, a binary matrix of DHB-aminopyrazine, $\mathrm{ZnO}$ nanoparticles, and Au nanoparticles were evaluated for their effectiveness as supporting materials in MALDI-MS analyses of glucose and sucrose. In all cases, sodiated peaks of both 
glucose and sucrose were observed. The lowest detection limits for both analytes ( 3 pmol) were obtained with carbon nanotubes. All of the evaluated materials suffered from poor reproducibility; the most reproducible results (RSD $<40 \%$ ) were observed with carbon nanotubes and the DHB-pyridine ionic liquid matrix at analyte loading between 33 and 333 pmol.

Acknowledgments. This work was supported by the Korea Research Foundation Grant funded by the Korean Government-2008-331-C00188, and also supported by the National Research Foundation of Korea through the Pioneer Research Center Program funded by the Ministry of Education, Science and Technology (No. M10711160001-08M1116-00110).

\section{References}

1. Chunyan, H.; Xiuli, M.; Shiping, F.; Zhiqiang, L.; Shuying, L.; Fengrui, S.; Juzheng, L. Rapid Commun. Mass Spectrom. 1998, 12,345 .

2. Grant, G. A.; Frison, S. L.; Yeung, J.; Vasanthan, T.; Sporns, P. J. Agr. Food Chem. 2003, 51, 6137.

3. Ren, S. F.; Zhang, L.; Cheng, Z. H.; Guo, Y. L. J. Am. Soc. Mass Spectr. 2005, 16, 333.

4. Su, C. L.; Tseng, W. L. Anal. Chem. 2007, 79, 1626.

5. McLean, J. A.; Stumpo, K. A.; Russell, D. H. J. Am. Chem. Soc. $\mathbf{2 0 0 5}, 127,5304$.

6. Chiu, T. C.; Chang, L. C.; Chiang, C. K.; Chang, H. T. J. Am. Soc. Mass Spectrom. 2008, 19, 1343.

7. Watanabe, T.; Kawasaki, H.; Yonezawa, T.; Arakawa, R. J. Mass Spectrom. 2008, 43, 1063.

8. Wei, J.; Buriak, J. M.; Siuzdak, G. Nature 1999, 399, 243.

9. Zhang, J.; Wang, H. Y.; Guo, Y. L. Chinese J. Chem. 2005, 23, 185.
10. Xu, S. Y.; Li, Y. F.; Zou, H. F.; Qiu, J. S.; Guo, Z.; Guo, B. C. Anal. Chem. 2003, 75, 6191.

11. Wang, C. H.; Li, J.; Yao, S. J.; Guo, Y. L.; Xia, X. H. Anal. Chim. Acta 2007, 604, 158.

12. Zabet-Moghaddam, M.; Heinzle, E.; Tholey, A. Rapid Commun. Mass Spectrom. 2004, 18, 141.

13. Tholey, A.; Heinzle, E. Anal. Bioanal. Chem. 2006, 386, 24.

14. Armstrong, D. W.; Zhang, L. K.; He, L.; Gross, M. L. Anal. Chem. 2001, 73, 3679 .

15. Crank, J. A.; Armstrong, D. W. J. Am. Soc. Mass Spectrom. 2009, 20, 1790.

16. Guo, Z.; He, L. Anal. Bioanal. Chem. 2007, 387, 1939.

17. Hashir, M. A.; Stecher, G.; Bonn, G. K. Rapid Commun. Mass Spectrom. 2008, 22, 2185.

18. Hashir, M. A.; Stecher, G.; Bakry, R.; Kasemsook, S.; Blassnig, B.; Feuerstein, I.; Abel, G.; Popp, M.; Bobleter, O.; Bonn, G. K. Rapid Commun. Mass Spectrom. 2007, 21, 2759.

19. Hashir, M. A.; Stecher, G.; Mayr, S.; Bonn, G. K. Int. J. Mass Spectrom. 2009, 279, 15.

20. Lee, H. S.; Yun, C. H.; Kim, H. M.; Lee, C. J. J. Phys. Chem. C 2007, 111, 18882.

21. Shen, L.; Bao, N.; Yanagisawa, K.; Domen, K.; Gupta, A.; Grimes, C. A. Nanotechnology 2006, 17, 5117.

22. Wu, H. P.; Su, C. L.; Chang, H. C.; Tseng, W. L. Anal. Chem. 2007, 79, 6215.

23. Mordkovich, V. Z.; Baxendale, M.; Yoshimura, S.; Chang, R. P. H. Carbon 1996, 34, 1301.

24. Eletskii, A. V. Phys. Usp. 2004, 47, 1119.

25. Nuutinen, J. M.; Purmonen, M.; Ratilainen, J.; Rissanen, K.; Vainiotalo, P. Rapid Commun. Mass Spectrom. 2001, 15, 1374.

26. Mohr, M. D.; Bornsen, K. O.; Widmer, H. M. Rapid Commun. Mass Spectrom. 1995, 9, 809.

27. Koichi, T.; Hiroaki, W.; Yutaka, I.; Satoshi, A.; Yoshikazu, Y.; Tamio, Y.; Matsuo, T. Rapid Commun. Mass Spectrom. 1988, 2 , 151. 